\title{
Geoarqueología y conservación del patrimonio en la antigua ciudad de Quilmes (Tucumán, Argentina)
}

\author{
M. Marta Sampietro Vattuone \\ (iD) http://orcid.org/0000-0002-7681-070X \\ Laboratorio de Geoarqueología, Facultad de Ciencias Naturales e Instituto "M. Lillo", Universidad Nacional de \\ Tucumán (UNT) - Consejo Nacional de Investigaciones Científicas y Técnicas (CONICET). Miguel Lillo 205 (CP \\ T4000), San Miguel de Tucumán, Tucumán, Argentina. E-mail: sampietro@tucbbs.com.ar

\section{José L. Peña Monné} \\ (iD) http://orcid.org/0000-0003-4067-8222 \\ Departamento de Geografía y Ordenación del Territorio, Universidad de Zaragoza. Pedro Cerbuna 12 (CP 50001), \\ Zaragoza, España. E-mail: jlpena@unizar.es
}

Recibido: 25 de marzo de 2020

Aceptado: 31 de julio de 2020

\section{Resumen}

La antigua ciudad de Quilmes se localiza en el valle del río Santa María, en el noroeste de la provincia de Tucumán (Argentina). El objetivo de este trabajo es presentar el estado de conservación y los procesos degradativos que la afectan desde una perspectiva geoarqueológica. La ciudad está ubicada en un área de conos aluviales coalescentes activos y laderas lo que facilitó el acceso al agua en el pasado. Sin embargo, en la actualidad las posibilidades de conservación se complican por la torrencialidad del sistema. La ciudad está repartida en tres zonas (A, B y C), cada una con sus propias características geomorfológicas y, por consiguiente, con problemas específicos a tener en cuenta. Los numerosos cauces fluviales procedentes de la Sierra de Quilmes generan procesos de erosión en las estructuras arqueológicas principalmente en el cono del río Las Agüitas en la zona A (sector no restaurado). Por otra parte, en el sector restaurado (zona B), la fuerte pendiente y la eliminación de la vegetación favorece la escorrentía superficial generando zonas de lavado intenso con movilización de sedimentos. Finalmente, el sector de producción agraria (zona C), instalado sobre el cono del río Los Candados es el menos afectado por estos problemas. 


\title{
Geoarchaeology and heritage conservation in the ancient city of Quilmes (Tucumán, Argentina)
}

\begin{abstract}
The ancient city of Quilmes is located in the Santa María Valley, northwest of Tucumán Province (Argentina). This paper aims to present its preservation state and the degradative processes affecting it and its productive area, from a geoarchaeological perspective. The city is located in an area of active coalescent alluvial cones, which provided easy access to water supplies in the past. However, today that position challenges its conservation, given the torrential nature of the system. Three areas can be distinguished in the city (zones $A, B$, and $C$ ), each one with its geomorphological characteristics and specific preservation problems that must be attended. The several fluvial courses coming from the Sierra de Quilmes give rise to erosion processes that affect the archaeological structures, mainly in the alluvial cone of Las Agüitas river (A zone), the non-restored area. In the restored area (B zone), the strong gradient and the elimination of the vegetation cover favor surficial runoff, generating areas with laminar erosion and sediment movement. Finally, the agrarian sector ( $C$ zone), settled over Los Candados river cone, is less affected by these problems.
\end{abstract}

KEYWORDS: Calchaquí Valley; Northwest Argentina; Quilmes Indian Community; Heritage degradation.

\section{Introducción}

La antigua ciudad de Quilmes se localiza en un sector central del valle de Santa María, en el piedemonte oriental de la Sierra de Quilmes, que se extiende entre Pie de Médano y la confluencia con el río Calchaquí. El valle de Santa María constituye una fosa tectónica ubicada al noroeste de la provincia de Tucumán, noreste de Catamarca y centro-sur de Salta. Durante el Holoceno superior, lapso también denominado tardío y que comprende los últimos 4200 años, este valle fue profusamente ocupado por poblaciones indígenas agroalfareras cuyos asentamientos son identificables en la actualidad.

Uno de los rasgos sobresalientes de la región, desde el punto de vista histórico/ arqueológico, es que fue una de las zonas que resistió de manera más consistente a la conquista y colonización hispanas entre los siglos XVI y XVII. Entre los asentamientos se destaca el de la antigua ciudad de Quilmes, que constituye el último bastión de resistencia de aquel período. La ciudad quedó abandonada durante mucho tiempo y a pesar de que es una zona que ha sido puesta en valor en época reciente y con diversos criterios, existen aspectos que no han sido abordados hasta la actualidad, y en muchos sentidos el asentamiento es prácticamente desconocido.

El objetivo de este trabajo es presentar el estado de conservación patrimonial y los procesos degradativos que afectan a la antigua ciudad de Quilmes y su área productiva desde una perspectiva geoarqueológica. Se consideran conjuntamente los principales rasgos que inciden tanto sobre la porción reconstruida como en la que no se han efectuado intervenciones y que se encuentra cercado, y al amplio sector de producción agraria, no estudiados hasta la fecha. Se ponen además en evidencia los procesos geomorfológicos que están influyendo (o pueden llegar a influir) negativamente en su conservación debido a las características de emplazamiento y a las condiciones áridas de la región. La ubicación del sitio en el ámbito geomorfológico de conos aluviales y laderas acrecienta enormemente la necesidad de aplicación de soluciones que favorezcan su conservación dado el dinamismo que caracteriza a estas formas. 


\section{Área de estudio}

La posición estratégica de la ciudad de Quilmes, en la parte central del valle de Santa María se completa con el control del corredor natural del valle del río Amaicha, que conecta el valle de Santa María con el de Tafí (Figura 1). El asentamiento se ubica sobre uno de los numerosos conos laterales que conectan con el gran cono formado por los ríos Los Candados y Quilmes, ambos afluentes del río Santa María, y se extiende por las primeras estribaciones de la Sierra de Quilmes. La cuenca conjunta de estos ríos es una de las más extensas de la vertiente oriental de la citada sierra, que recoge las aguas de varias quebradas importantes (Figura 1). La cabecera principal del río Quilmes se interna diagonalmente en la Sierra homónima siguiendo una falla que permite una comunicación sencilla con la cabecera del río Colorado, curso alto del río Santa María.

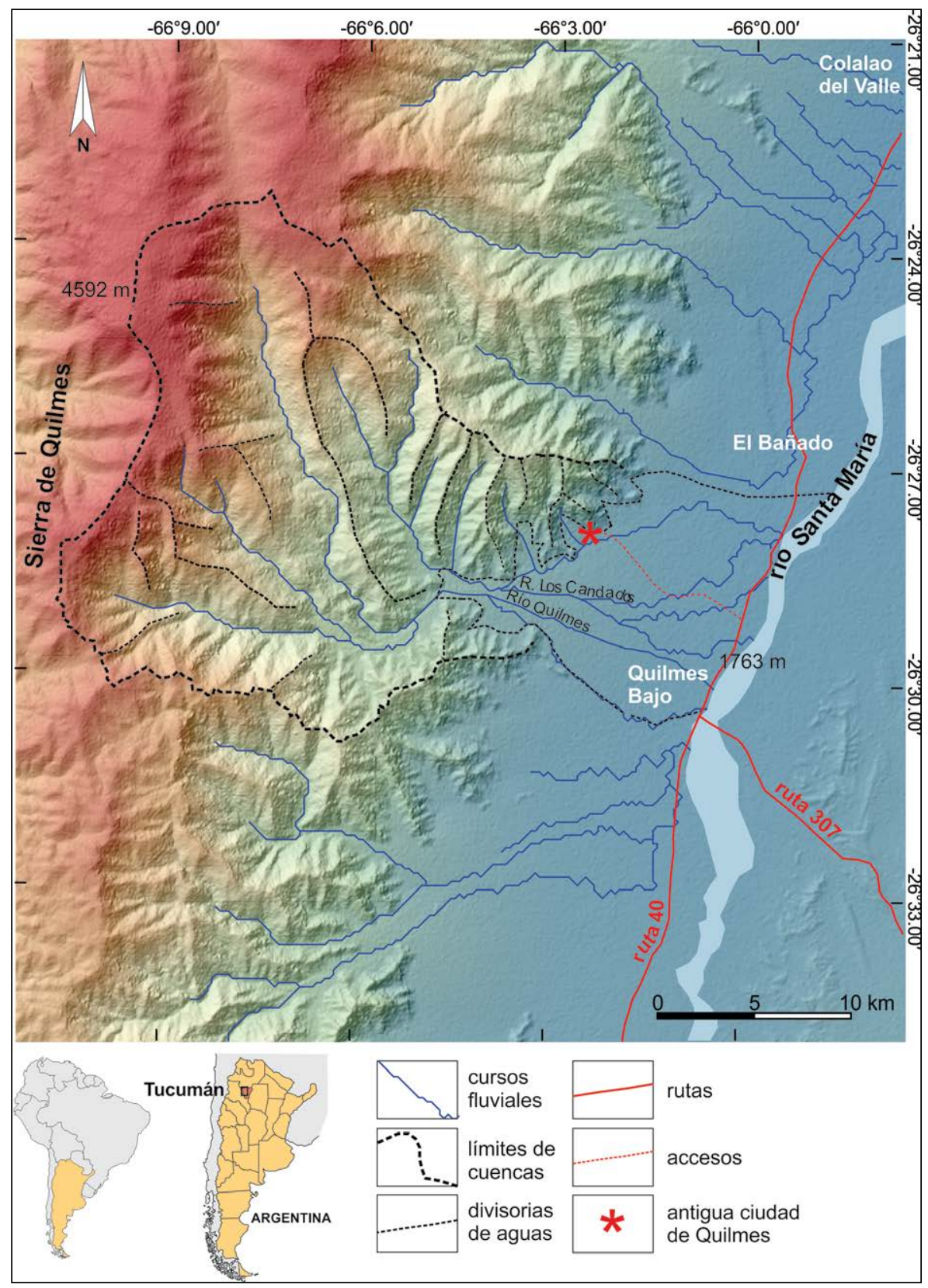

Figura 1. Mapa de situación de la cuenca y cono aluvial de los ríos Los Candados y Quilmes, en la vertiente oriental de la Sierra de Quilmes y ubicación del sitio arqueológico. 
La altura máxima de su divisoria es de 4592 m s.n.m., y su curso se abre en la sección baja para formar un gran abanico aluvial ocupado por varios canales hasta alcanzar la confluencia con el río Santa María, a $1763 \mathrm{~m}$ s.n.m. El abanico aluvial conjunto de los ríos Quilmes y Los Candados es uno de los que forman el piedemonte oriental de la Sierra de Quilmes desde Cafayate, al norte, hasta Punta Balasto, al sur. Son abanicos coalescentes depositados por la red de drenaje que desciende de la sierra y tienen como nivel de base el río Santa María. Las grandes masas de sedimentos y bloques fueron acumuladas durante el Cuaternario, como producto de la erosión de las rocas metamórficas y graníticas que componen el macizo montañoso (Peña Monné y Sampietro Vattuone, 2016). En general, salvo algunos relictos más antiguos muy escasos, todo el piedemonte está formado por acumulaciones del Holoceno medio-superior que conservan gran dinamismo en la actualidad (Peña-Monné y Sampietro-Vattuone, 2018).

La antigua ciudad de Quilmes se asienta en uno de los abanicos aluviales afluentes adosados lateralmente al abanico aluvial de Los Candados-Quilmes, así como en otra pequeña cuenca vecina (Figura 1). Todo el conjunto está limitado por las estribaciones rocosas de la sierra, por cuyas laderas se prolongan las estructuras del núcleo habitacional y algunas terrazas de cultivo. Por otra parte, la zona agrícola se extendía sobre la parte norte del abanico aluvial principal de Los Candados-Quilmes más próximo a la ciudad. Desde el punto de vista constructivo, la ciudad es similar a otros asentamientos contemporáneos de la zona y constituyó el último baluarte tras 130 años de resistencia al dominio español (Montes, 1961), razón por la cual posee gran valor simbólico. Después de la derrota, la ciudad fue desalojada de manera forzada (Giudicelli, 2013), y a fines de 1800 fue "descubierta" por la comunidad científica argentina (Ambrosetti, 1897) en el marco de las grandes exploraciones realizadas al Noroeste Argentino (NOA) orientadas a arqueología y etnografía.

La ciudad fue parcialmente puesta en valor como parte del Plan NOA Turístico de los años '70 y ' 80 , con el desarrollo del Programa de Recuperación de Patrimonio Histórico Cultural de la Provincia (Pelissero y Difrieri, 1981), duramente cuestionado en la actualidad (Schávelzon, 1990; Sosa, 2007). Posteriormente, en 1992 se realizó la concesión para su explotación privada durante 10 años, en el marco de las políticas neoliberales dominantes desde el gobierno de turno, lo cual impactó fuertemente de manera negativa sobre el patrimonio arqueológico del sector. En la actualidad la antigua ciudad de Quilmes se encuentra bajo la administración de un sector de la Comunidad India Quilmes y se constituye como un estandarte de los reclamos identitarios de la comunidad (Becerra et al., 2013; Bidaseca y Ruggero, 2010; Marchegiani, Palamarczuk, Pratolongo y Reynoso, 2006; Rodríguez, Sampietro Vattuone y Peña Monné, 2016). Se ha construido un Centro de Interpretación donde se exponen algunos objetos de la cultura material del sitio, los mitos fundacionales, cierta información sobre vida cotidiana y aspectos relativos a la conquista hispana.

\section{Metodología}

Para evaluar el estado de conservación, identificar los procesos activos y valorar la incidencia de los diversos factores degradativos en el área de estudio se realizó en primera instancia la fotointerpretación de fotografías aéreas de la zona pertenecientes al Plan Cordillera Norte (servicio aéreo: Spartam Air Service; año del vuelo 1969) completado con el análisis visual de imágenes satelitales Google Earth (2019). Esto permitió valorar la evolución de la zona e identificar los rasgos degradativos a través de los últimos 50 años en la evolución del sitio.

Además, en el año 2016 se realizó un vuelo fotográfico privado en avioneta con el objeto de tener fotografías oblicuas de baja altura. A continuación, para obtener datos 
de mayor detalle, se realizó un vuelo fotogramétrico (2018) con drone DJI Phantom 4, a $100 \mathrm{~m}$ de altura, con superposición entre fotogramas del $80 \%$. Las 774 fotos resultantes se procesaron con Agisoft Photoscan v.4.01 obteniendo un ortomosaico que abarca $1,02 \mathrm{~km}^{2}$, correspondientes a casi la totalidad del sector urbanizado, la zona reconstruida y una parte de la zona agrícola. La resolución en terreno es 3,49 $\mathrm{cm} /$ pixel. También se obtuvieron fotografías oblicuas de 12,4 Mpx de determinadas zonas para completar la información.

Finalmente, los sensores remotos fueron complementados con prospección sistemática sin recolección de material y control de campo de las observaciones de gabinete. Estos datos se utilizaron para la realización de cartografías comparadas de la ciudad entre 1969 y 2019 y para registrar puntualmente las zonas con problemas de conservación relacionados con los procesos geomorfológicos activos.

\section{Resultados}

Las observaciones realizadas permiten sectorizar la zona de estudio en tres partes principales: la zona urbana, dividida en (A) la zona sin afectar por actuaciones recientes y (B) el sector reconstruido, y (C) la zona de explotación agrícola (Figura 2A).

Como se ha indicado anteriormente, la zona urbana de Quilmes se ubica mayormente en un abanico aluvial coalescente al abanico principal conjunto de los ríos Los Candados y Quilmes, así como en zonas de laderas de fuerte pendiente. La gran ventaja es que el acceso a fuentes permanentes de agua está garantizado, pero al mismo tiempo constituyen ambientes geomorfológicos de alta capacidad erosiva por las características áridas de la región, lo que trae consigo problemas de conservación dada la dinámica torrencial que les caracteriza.

La cuenca general se compone de cuatro grandes segmentos fluviales. Los tres meridionales se unen para formar el río Quilmes poco antes de salir del marco montañoso. Sin embargo, el canal más septentrional o río Los Candados, no llega a confluir con el río Quilmes, por lo que ambos discurren paralelos por el ápice del abanico sin llegar a unirse del todo, excepto en el sector medio donde llegan a producirse avulsiones en momentos de crecida (Figura 1). Entre ambos configuraron el cono de Los Candados-Quilmes. El cauce del río Los Candados se divide aguas abajo en varios brazos también divergentes que discurren por la antigua zona agrícola de la ciudad de Quilmes (zona C en la Figura 2A), y su brazo más septentrional se unía con los diversos cursos torrenciales que se extienden por el cono del río Las Agüitas (zona $A$ en la Figura $2 A$ ) donde se sitúa una parte de la ciudad, para dirigirse hacia el este (zona B en la Figura 2A). Actualmente, la construcción de un muro de defensa de $200 \mathrm{~m}$ de longitud construido en la década del ' 90 ( $m$ en Figura 2A) produce el desvío del cauce más septentrional del río Los Candados hacia otros canales más meridionales. Esta obra supone la principal defensa preventiva para la ciudad al reducir gran parte de la peligrosidad fluvial. A partir de su construcción, sólo los canales del cono de la propia ciudad (río Las Agüitas) suponen un problema erosivo potencial por agua encauzada.

Como primer paso para el reconocimiento visual de los problemas degradativos que afectan al área del yacimiento, se ha analizado la fotografía aérea del Plan Cordillera Norte (1969) (Figura 2B). Esta imagen permite reconocer la situación general hace 50 años para poder compararla con la imagen de 1969 de la Figura 2A. Para ello se ha remarcado en rojo el trazado de los muros de la zona urbana, que era entonces mucho más visible que en la imagen actual. Igualmente pueden apreciarse perfectamente la disposición y características de los cursos fluviales que discurren por el área y las 

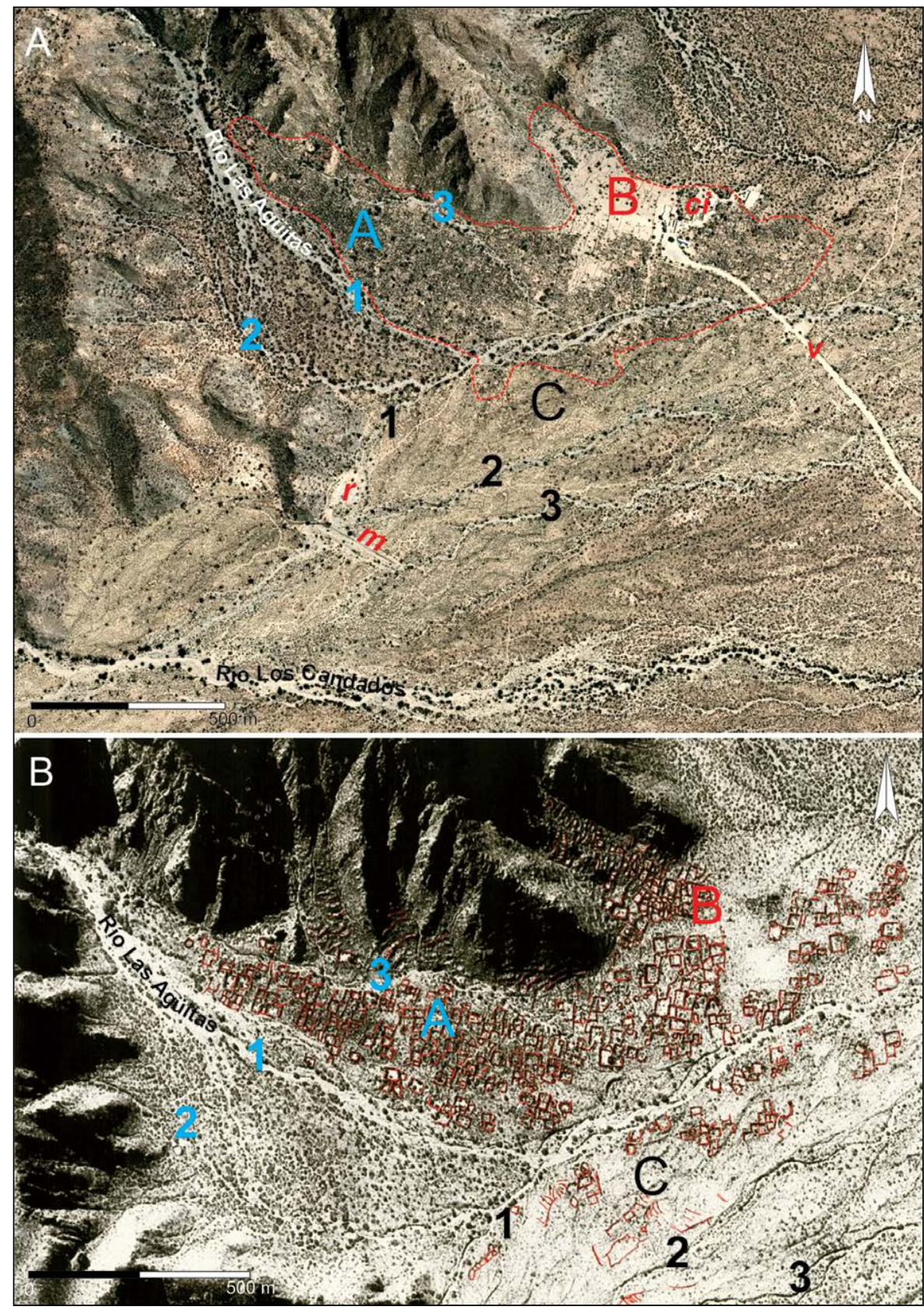

Figura 2. Imágenes del área de estudio. A) Imagen satelital (Google Earth, 2019): A) cono aluvial del río Las Agüitas (canales 1 a 3); B) sector urbano reconstruido y centro de interpretación (ci); C) sector agrícola sobre el cono aluvial del río Los Candados (canales 1 a 3); m) muro de defensa; r) represa prehispánica; B) Fotografía aérea (Spartam Air Service, 1969). Se indican estructuras arqueológicas cartografiadas y los sectores determinados.

zonas de mayor afección potencial del yacimiento, que serán descritas con mayor detalle siguiendo la división propuesta en la Figura 2A.

La zona A corresponde al cono aluvial del río Las Agüitas, curso torrencial que fluye hacia el cauce norte (1) del río Los Candados. A la salida del área montañosa, el río Las Agüitas inicia su cono que se expande de forma disimétrica, con una mayor amplitud hacia el Noreste (zona B). Ya en el cono, recibe otros afluentes menores, pero también altamente torrenciales, que le aportan mayor dinamismo hasta la zona distal. El cono está surcado por un canal principal, a veces dividido en dos cauces paralelos (Figura 3A), que 


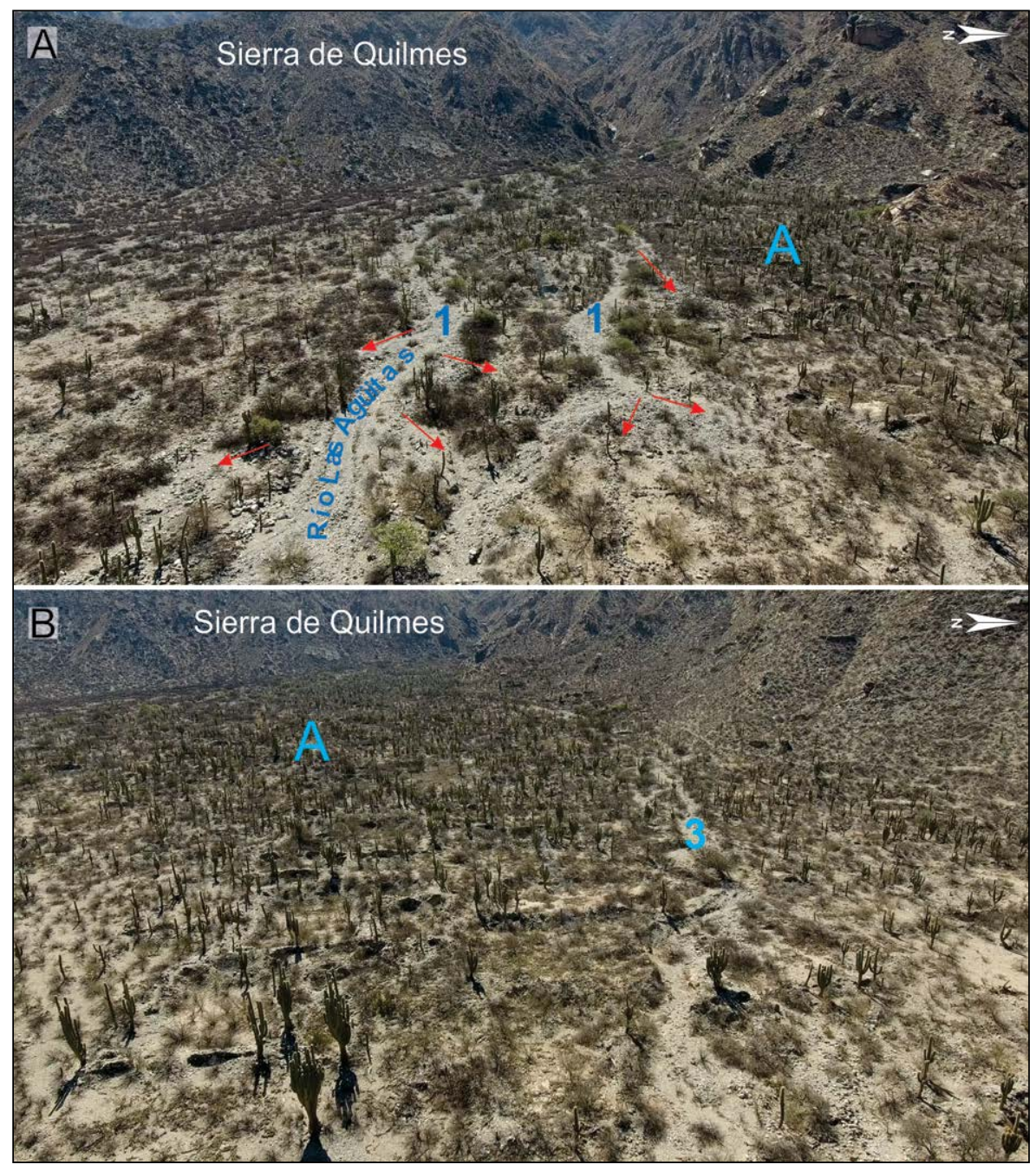

Figura 3. A) Zona apical y media del cono del río Las Agüitas, con el canal principal (1) subdividido en este punto en dos cauces paralelos de los que desbordan (flechas rojas) coladas de debris flow, que afectan al yacimiento arqueológico (derecha de la imagen); B) Sector oriental del cono (zona A), con el cauce 3 del río Las Agüitas recorriendo el pie de las laderas y atravesando la zona urbana, de la que se aprecian los restos de muros (tomadas con drone).

discurre aproximadamente por su zona central (1 en Figura 2); otro canal (2 en Figura 2) se separa del principal y reúne los aportes de los torrentes del suroeste. En esta parte el cono queda limitado por varios relieves que provocan el giro del canal 2 para unirse al canal 1 aguas abajo; en el mismo sector, estos canales se unían con el cauce norte del río Los Candados antes de que fuera desviado artificialmente hacia el este. Este tramo del cauce se sigue manteniendo muy activo gracias al importante aporte del río Las Agüitas. Por último, un tercer canal ( 3 en Figura 2) discurre adosado al contacto del cono con los relieves del noreste (Figura 3B), uniéndose al curso anterior antes de alcanzar la zona B. Estos cursos permiten dividir el cono en dos segmentos de diferente dinamismo, siendo mucho mayor el meridional. La distribución de estructuras residenciales indica que durante la ocupación Quilmes la distribución de la actividad fluvial debió ser similar. Durante tiempos prehispánicos sólo el sector norte del abanico fue habitado. Las construcciones residenciales ocupan casi la totalidad de la superficie de este sector formando un entramado geométrico irregular, con predominio de muros rectos y casas cuadrangulares acompañadas de estructuras circulares de almacenamiento.

El río Las Agüitas y sus afluentes, dadas sus elevadas pendientes, transportan materiales gruesos, gravas y bloques, tamaño que sólo disminuye en la zona distal. El 
río muestra gran actividad en su ápice y zona media, con barras de gravas y canales múltiples de tipo trenzado (braided) (Ramos, 1992) y con lóbulos de flujos de detritos (debris flow) que penetran hacia los canales de menor orden. Como hemos indicado, la parte situada al norte del río Las Agüitas queda más separada de la acción directa del río y también se ve afectada por la llegada de agua y sedimentos de los torrentes laterales, aunque con mayor presencia de materiales finos que se expanden sobre el área del yacimiento. El dinamismo de los canales es mucho más visible en la imagen de 1969 que en la actualidad (Figura 2), posiblemente porque el área ha recuperado una mayor cobertura vegetal. La zona urbana instalada sobre este segmento del cono queda rodeada por los cauces mencionados ( 1 y 3 ), afectando principalmente a sus márgenes. En el río Las Agüitas (1) son frecuentes los canales trenzados y duplicación de canales que ejercen incisiones puntuales y erosión lateral que afectan a algunos edificios, con derrumbes de sus muros, dejando aislados algunos de ellos entre canales (Figura 4A). Además, a pesar de la existencia de una cierta cubierta vegetal, se producen desbordamientos de lóbulos de gravas rompiendo las márgenes, así como penetración de sedimentos finos hacia los restos de las construcciones. Este efecto aumenta aguas abajo, en las casas de la parte distal (Figura 4B). De la misma forma, en el cauce septentrional (3), aunque es un curso menos caudaloso, se producen efectos semejantes debido a que el canal es menos profundo, con desbordes puntuales de flujos de detritos y aguas cargadas de sedimentos finos que penetran en el interior de los muros y rellenan los silos circulares, de tal manera que algunos apenas sobresalen entre los depósitos recientes (Figuras 4C y 4D).

Por último, la parte con mayor actividad dinámica por efecto de la acumulación de caudales es el antiguo cauce norte del río Los Candados, que va recogiendo los sucesivos canales. Este sector presenta casas en ambas márgenes, y se destacan los efectos del río en la parte sur, junto a la zona agrícola C (Figura 2A). Presenta morfología de canales trenzados (braided) con tendencia a ampliaciones laterales del lecho, especialmente a partir de la confluencia del canal principal (1) del río Las Agüitas. Las casas reciben sobre todo sedimentos finos que han rellenado gran parte de los recintos $y$, como puede apreciarse en las imágenes, provoca encharcamientos (Figura 4E). El canal principal choca con los muros de algunas casas al desplazarse lateralmente, con los consiguientes derrumbes y acumulaciones de gravas (Figura 4F). En los espacios más alejados de los canales de escorrentía principales, no afectados por tanto por la dinámica fluvial, la conservación de los muros es mucho mejor, alcanzando alturas superiores a 1,5 $\mathrm{m}$, y parece que la mayoría de los derrumbes son debidos principalmente a la escasa consistencia constructiva de los mismos. Finalmente, también se verifica la existencia de casas y graderíos de terrazas de cultivo ascendiendo por las laderas y algunos de los fondos de los torrentes laterales, muy degradados por la erosión de las citadas laderas acompañadas por desplazamientos de grandes bloques.

La zona B es el sector más conocido de la antigua ciudad de Quilmes ya que en parte del mismo se han reconstruido los muros y es actualmente visitable (Figura $5 A$ ). Presenta una superficie llana, en continuidad con la zona A (Figura 2A), al este del cauce 3 del cono de Las Agüitas (Figura 5B) y se extiende hacia la prolongación del viejo cauce septentrional de Los Candados. Además, la ciudad se adosa hacia dos estrechos espolones rocosos y el espacio intermedio, por donde ascienden los muros escalonados (Figura $5 \mathrm{C}$ ). Este sector entre las dos alineaciones rocosas conforma una cuenca alargada, con abundantes bloques caídos de las laderas marginales y cuyo cono se prolonga por la zona llana inferior. A diferencia de la zona A, aquí la cubierta vegetal ha desaparecido, a excepción de algunos cardones dispersos, como parte del proceso de reconstrucción; por otra parte, la fracción gruesa de la superficie del terreno es eliminada intencionalmente como parte de las labores de mantenimiento, de manera que no hay verdaderos obstáculos al movimiento de escorrentía superficial del agua de lluvia; además las zonas de tránsito indicadas entre terrazas y unidades 

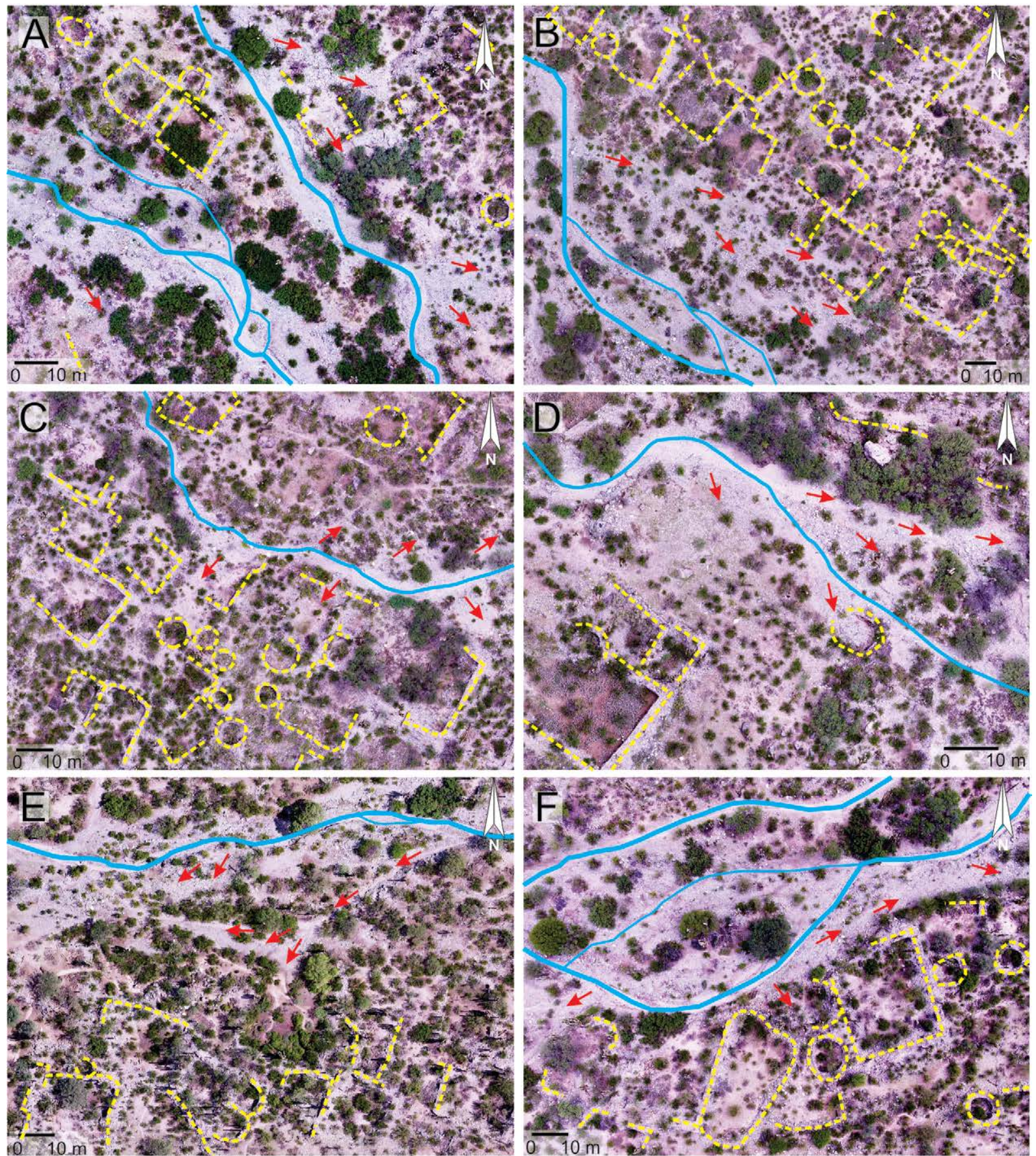

Figura 4. Imágenes aéreas a baja altura de los efectos geomorfológicos de los cauces del río Las Agüitas (líneas azules) en el área urbana del cono aluvial (zona A); $A$ y B) canales de gravas del cauce 1 de Las Agüitas con penetraciones laterales (flechas rojas) en las estructuras residenciales; $C$ y $D$ ) canales del cauce 3 desbordando sedimentos gruesos y finos que rellenan las estructuras rectangulares y circulares; $E$ y $F$ ) cauce norte (1) del rio Los Candados tras su confluencia con el río Las Agüitas, con trazado braided desbordando hacia las estructuras residenciales, rellenar parcialmente por sedimentos finos (líneas amarillas perfilando muros; base: ortomosaico).

residenciales presentan fuerte compactación por el paso de visitantes. La conjunción de estos factores genera el marco adecuado para que se produzca un intenso lavado del material fino y la formación de incisiones en algunos puntos, y muestra de ello es el lento descalce de las raíces de la vegetación (Figura 5D).

La erosión propia del sistema ya debía ser importante durante el poblamiento y tuvo que aumentar durante el largo período de abandono posterior, tal como se observa en 

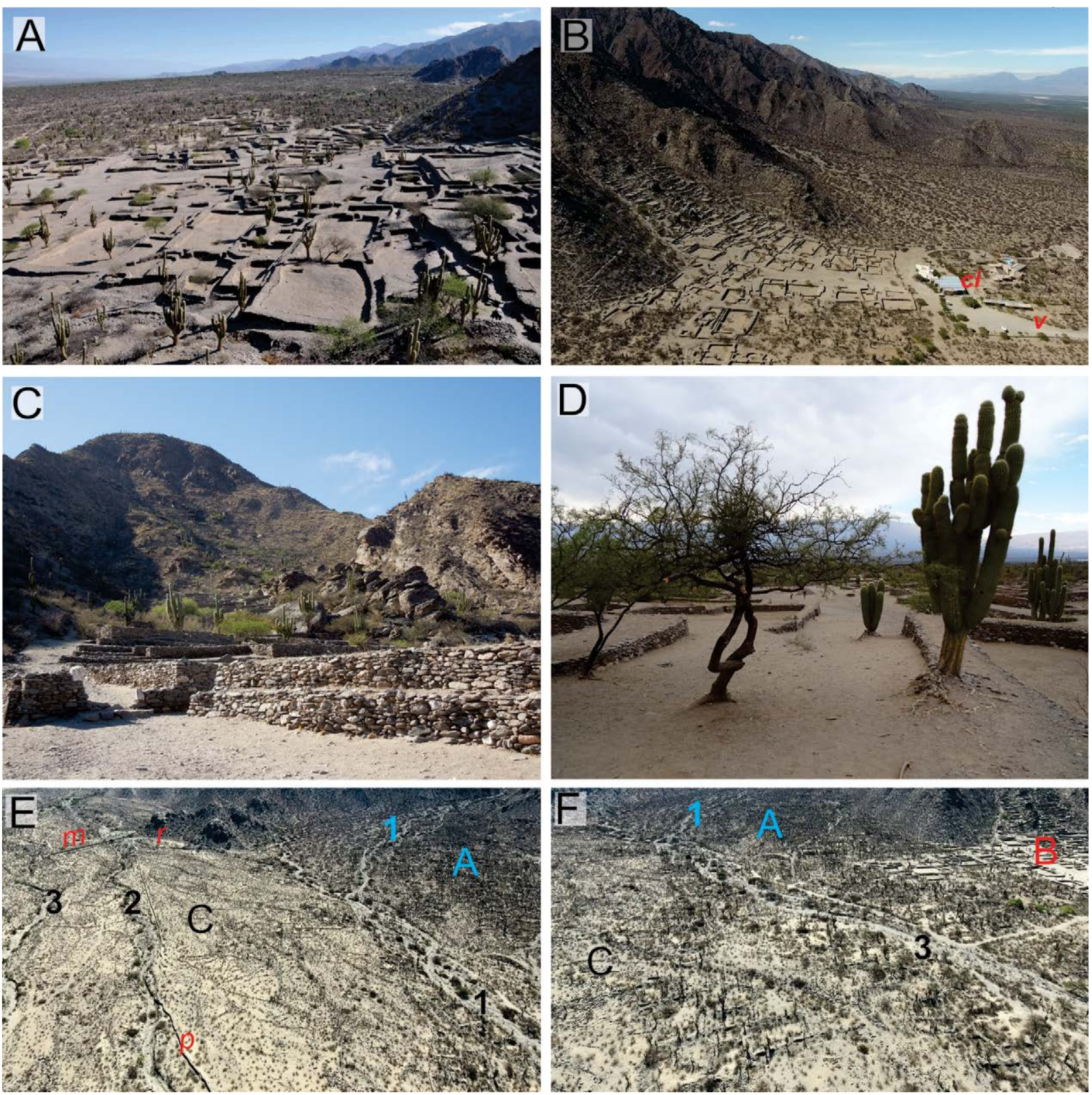

Figura 5. Zona B. A) vista general del cono de los ríos Quilmes y Los Candados y área reconstruida de la ciudad, con grandes espacios sin cubierta vegetal; B) sector llano y laderas del área reconstruida, con situación de la vía de acceso (v), el centro de interpretación y el hotel (ci) (vuelo 2016); C) estructuras arqueológicas ascendiendo entre los dos espolones rocosos, con grandes bloques deprendidos, y camino de acceso que sirve de canal de escorrentía; D) descalce erosivo de las raíces de los cardones por el lavado de materiales finos. Imágenes de la superficie agrícola (zona C); E) estructuras agrarias entre los cauces 1 y 3 del rí Los Candados, con unidades residenciales en su margen derecho; al fondo, el muro de defensa (m) y la represa prehispánica (r); en el centro, pared perimetral reciente (p); $F$ ) vista general de la zona agrícola (C) y su relación espacial con las dos áreas urbanas $(A, B)(5 E$ y $5 F$ imágenes de drone).

la imagen del año 1969 (servicio aéreo Spartam Air Service), anterior a los trabajos de restauración de este sector de la ciudad (Figura 2B). Desde entonces la degradación en conjunto del sitio se ha visto potenciada por la ejecución de diversas obras civiles y comerciales que han comprometido la integridad del área. Entre ellas se cuentan la vía de acceso al sitio construida en los '70, el hotel edificado en la década del ' 90 y construcciones erigidas recientemente. Dentro de estas últimas pueden mencionarse el Centro de Interpretación y feria y la generación de un amplio espacio de estacionamiento para vehículos (Figura 2B). Algunas de estas innovaciones constructivas, pensadas para llevar a los visitantes hasta el mismo corazón de Quilmes, se han efectuado sobre el área del sitio arqueológico, destruyendo una parte del mismo y sin que exista ningún 
tipo de registro de los materiales encontrados, ni constancia de que se realizaran las excavaciones de rescate pertinentes (Schávelzon, 1990).

La zona (C) de producción agraria se encuentra hacia el sur del asentamiento urbano, ocupando el cono aluvial del río Los Candados. A pesar de que las imágenes de 1969 y 2019 pertenecen a distintos soportes (analógico y digital) y que entre ambas existen distorsiones propias de los sistemas de captura de cada época, es posible compararlas teniendo en cuenta estas condiciones. Entre ambos años se observa un aumento importante en la dinámica de este canal que ha afectado por erosión lateral en todo su recorrido a las unidades residenciales existentes y a estructuras agrícolas (Figura 2). La zona se extiende desde el sector en que el río Los Candados se bifurca en cursos divergentes y aumenta su superficie, especialmente a partir de la defensa mencionada, que desvía los cursos septentrionales más al sur. Los restos de terrazas agrícolas se extienden entre dos de los cauces del río ( 1 y 3 en Figura $5 E$ ), quedando además un cauce intermedio (2) -no funcional desde la construcción del muro de defensa- que divide este espacio en dos zonas (Figura 5E). Una represa prehispánica ( $r$ en Figura 2A) para contener agua que posiblemente se usó para el riego de esta zona agrícola, se conserva parcialmente al norte del muro de defensa. En la parte más próxima a la ciudad, entre la zona agrícola y el canal norte del río Los Candados, se aprecian las casas de un conjunto marginal muy afectado por los antiguos canales que circularon por la zona y la erosión lateral del río (Figura 5F).

Aunque todos los cursos fluviales del área generan una importante erosión, la zona agrícola se conserva relativamente bien, dominando los procesos de lavado superficial de materiales finos por arroyada difusa y erosión laminar (sheet flood y rill wash) y la acción del viento. Solamente hay un elemento negativo y es la presencia de una larga pared ( $p$ en Figura 5E) construida en época reciente que atraviesa la zona en sentido noreste-sudeste, con algunos tramos derruidos, que en absoluto se ha trazado por los límites de la zona arqueológica sino por el medio, rompiendo la continuidad de la zona agrícola y generando un efecto visual negativo en el paisaje.

\section{Discusión y conclusiones}

La sectorización realizada en la zona de estudio, acompañada del análisis multitemporal permite visualizar cambios relacionados a la dinámica propia del régimen torrencial de los ríos de la zona. En ambientes áridos y semiáridos es usual la ocurrencia de lluvias localizadas de corta duración y gran intensidad que producen crecidas súbitas (flash flood) de los arroyos. Además, la escasa cobertura vegetal y el material disponible favorecen la generación de flujos de detritos (debris flow). Procesos semejantes son abundantes en cauces similares de conos cercanos como en Pichao (Peña-Monné, Sampietro-Vattuone, Maldonado, Cano y Aguirre, 2016a), que forma parte también del piedemonte oriental de la Sierra de Quilmes y comparte las características intrínsecas de su formación (Peña-Monné, Sampietro-Vattuone, Maldonado, Cano y Aguirre, 2016b). En ambos casos, los abanicos aluviales sobre los que se asientan los sitios arqueológicos conforman lo que se ha denominado Unidad H2 (Peña-Monné y Sampietro-Vattuone, 2016) que, de acuerdo con el modelo evolutivo existente para la región, abarca la época comprendida entre el ca. 4200 AP y 600 AP (Sampietro-Vattuone y Peña-Monné, 2016; Sampietro-Vattuone et al., 2018).

La fotografía aérea de 1969 del sector de la antigua ciudad de Quilmes refleja gran actividad sobre el sector apical y medio del cono aluvial del río Las Agüitas, afectando parte de la zona urbana (A) donde dominan canales múltiples de baja sinuosidad (Leopold y Wolman, 1957; Schumm, 1985) adaptados a la abundante carga tractiva que transportan y fuerte pendiente (Rust, 1978). El cono está formado por sedimentos 
que muestran estructuras internas típicas de corrientes fluviales y flujos densos (debris flow). En la actualidad, los problemas derivados de la actividad geomorfológica se centran principalmente en las márgenes de los canales fluviales tanto del río Las Agüitas como Los Candados. En estos ambientes, las avenidas esporádicas en forma de flujos activan los canales trenzados (braided) que normalmente tienden a ampliarse lateralmente (Leopold, Wolman y Miller, 1995), en este caso actuando en las márgenes de las barras y en las estructuras arqueológicas. También las zonas arqueológicas en las laderas de Quilmes se ven afectadas por las caídas de bloques por gravedad, procesos de reptación, paso de ganado y presencia de regueros (rills) por escorrentía superficial.

Los análisis similares realizados en El Pichao muestran la prevalencia del mismo tipo de procesos vinculados a la dinámica de canales trenzados, aunque en Pichao también se observan desbordamientos del canal principal en forma de flujos de barro (mudflow) y flujos de detritos de mayor importancia (Peña Monné et al., 2016a, 2016b). Estas diferencias están vinculadas a los tamaños de las respectivas cuencas aguas arriba del ápice de los conos, dado que la cuenca del río Las Agüitas es mucho menor que la del río Pichao., aunque con exposición similar, Respecto a las laderas los procesos son similares, aunque en El Pichao la existencia de gran cantidad de material metamórfico meteorizado disponible en el Cerro Condorhuasi genera el desarrollo de conos de derrubios al pie de la ladera que no se observan en nuestro caso de estudio.

La pared $(p)$ artificial que corta el sector $C$ fue realizada con la intención de minimizar el paso de ganado sobre el yacimiento. Sin embargo, además de que genera un impacto visual negativo y que parte la zona de exploración agrícola por la mitad, presenta muchos sectores con derrumbes, con lo cual su eventual acción preventiva es limitada. Finalmente, el material de construcción es local, por lo que fue extraido de las estructuras de las inmediaciones y los cursos de agua.

Tal como se desprende de la documentación gráfica presentada, el curso 1 del río Los Candados presentaba serios problemas para la integridad del sitio, lo que ha sido mitigado con la construcción de la defensa (aunque parte de la zona agrícola se encuentra aguas arriba de la misma); las dimensiones de la construcción suponen además la anulación del curso 2 derivando el caudal hacia el 3 que atraviesa una zona muy marginal de la zona agraria con resultados adecuados desde el punto de vista de la conservación del área.

Considerando el sitio arqueológico en conjunto, aunque la zona tiene alto dinamismo geomorfológico, hay áreas muy extensas sin riesgos de conservación, como son las partes internas de la zona A y C. En la parte no restaurada la presencia de cierto recubrimiento vegetal impide la acentuación de los proceso de escorrentía, mientras que en las partes restauradas y visitables se aprecia la acción de la arroyada superficial al no tener vegetación y ser zonas de circulación compactadas por el paso de los visitantes. Por último, el impacto paisajístico de la ruta y las construcciones efectuadas es máximo, contraviniendo las prácticas habituales (Schávelzon, 1990) de protección al haberse situado en pleno sitio arqueológico y afectando incluso a parte de las estructuras.

Desde una perspectiva consevacionista la torrencialidad del río Las Agüitas hace conveniente la planificación de un sistema de desvíos y encauzamiento escalonado que minimice la erosión en profundidad y lateral y los desbordes que aportan gravas y materiales finos a las estructuras que bordean los cursos en la zona A. Resulta esencial evitar el ensanchamiento de los canales, sobre todo en la zona más baja del cono de Las Agüitas y tras la confluencia con el canal 1 de Los Candados, para lo que resultaría necesaria la construcción de diques de gaviones que frenen la velocidad del 
flujo en momentos de crecida. Dentro de la zona reconstruida (B) es prudente evitar la remoción manual de los pavimentos de gravas que se forman naturalmente por erosión laminar. La zona (C) agraria no presenta necesidades de conservación específicas; por otra parte, es el sector menos conocido y precisa un estudio profundo desde el punto de vista arqueológico.

Este trabajo consituye la primera aproximación al estudio de la antigua ciudad de Quilmes desde una perspectiva geoarqueológica, considerando los aspectos vinculados a su conservación para evitar la degradación de la misma a mediano y largo plazo. La metodología utilizada demuestra ser adecuada para la realización de sencillas propuestas de conservación aplicables, previo análisis específicos, a otros sitios arqueológicos de la zona.

\section{Agradecimientos}

Esta es una contribución del grupo de investigación Primeros Pobladores del Ebro (Gobierno de Aragón y Fondo Social Europeo) y se engloba en los intereses del Instituto Universitario de Estudios Ambientales de Aragón de la Universidad de Zaragoza (IUCA). Ejecutada con fondos de los proyectos PIP 837 CONICET, PIUNT G629 y PICT 20181119 (Argentina). Agradecemos a la Comunidad India Quilmes (Provincia de Tucumán), los miembros de la base de Quilmes, al cacique Sr. Francisco Chaile, la delegada de base Sra. Laura Liendro y el Sr. Pablo Fabián que nos acompañaron a lo largo de la investigación. Agradecemos a los evaluadores por la revisión crítica del manuscrito. 


\section{Referencias citadas}

» Ambrosetti, J. B. (1897). La antigua ciudad de Quilmes (Valle Calchaquí). Boletín del Instituto Geográfico Argentino, XVIII(1-3), 33-70.

» Becerra, M. F., Crespo, C., Pierini, M. V., Ramírez, V., Rodríguez, L., Sidy, B. y Tolosa, S. (2013). Dinámicas de poder y saber en la reconstrucción de la Ciudad Sagrada de Quilmes (Tucumán 1977-1981). Alteridades, 23(46), 67-77. https://alteridades.izt.uam.mx/index.php/Alte/ article/view/756 (Acceso: 1 de enero, 2020).

» Bidaseca, K. y Ruggero S. (2010). Disputas en torno a la ciudad sagrada-ruinas de Quilmes. Memoria e identidad en la Comunidad India Quilmes. Breves Contribuciones del Instituto de Estudios Geográficos, 21(21), 85-103. http://ojs.filo.unt.edu.ar/index.php/bcieg/article/ view/187 (Acceso: 1 de enero, 2020).

» Giudicelli, C. (2013). Hablar la lengua del enemigo: la soledad del misionero en tierras Calchaquíes. Tempo, 19(35), 1-22. https://doi.org/10.5533/TEM-1980-542X-2013173504

» Leopold, L. B. y Wolman, M. G. (1957). River channel patterns: Braided, meandering, and straight. Physiographic and Hydraulic Studies of Rivers. Washington, D.C.: Geological Survey Professional Paper 282-B, U.S. Department of the Interior, U.S. Government Printing Office. https://doi.org/10.3133/pp282B

» Leopold, L. B., Wolman, M. G. y Miller, J. P. (1995). Fluvial processes in Geomorphology. Nueva York: Dover Publications.

» Marchegiani, M., Palamarczuk, V., Pratolongo, G. y Reynoso, A. (2006). Nunca serán ruinas: visiones y prácticas en torno al antiguo poblado de Quilmes en Yocavil. En A. Austral y M. Tamagnini (Eds.), Problemáticas de la Arqueología Contemporánea (Tomo I, pp. 313-323). Río Cuarto: Universidad Nacional de Río Cuarto.

» Montes, A. (1961). Encomienda de indios diaguitas documentados en el Archivo Histórico de Córdoba. Revista del Instituto de Antropología, 2-3, 7-29.

» Pelissero, N. y Difrieri, H. (1981). Quilmes. Arqueología y Etnohistoria de una Ciudad Prehispánica. San Miguel de Tucumán: Gobierno de la Provincia de Tucumán y Universidad de Buenos Aires.

» Peña Monné, J. L. y Sampietro Vattuone, M. M. (2016). Geomorphology of the alluvial fans in Colalao del Valle-Quilmes (Santa María Valley, Tucuman Province, Argentina). Journal of Maps, 12(1), 460-465. https://doi.org/10.1080/17445647.2016.1239230

» Peña Monné, J. L. y Sampietro Vattuone, M. M. (2018). Evolución geomorfológica de los conos aluviales de los ríos Pichao y Managua (valle de Santa María, Prov. de Tucumán, Argentina). En R. Blanco Chao, F. Castillo Rodríguez, M. Costa Casais, J. Horacio García y M. Valcárcel Díaz (Eds.), Xeomorfologxía e paisaxes xeograficas. Catro décadas de investigación e ensino. Homenaxe a Augusto Pérez Alberti (pp. 431-449). Santiago de Compostela: Universidad de Santiago de Compostela.

» Peña Monné, J. L., Sampietro Vattuone, M. M., Maldonado, M. G., Cano, S. F. y Aguirre, M. G. (2016a). Contexto geomorfológico y problemas de conservación en el sitio arqueológico El Pichao (valle de Santa María, Noroeste Argentino). En M. M. Sampietro-Vattuone y J. L. PeñaMonné (Eds.), Geoarqueología de los Valles Calchaquíes (pp. 165-184). Tucumán: Laboratorio de Geoarqueología, Universidad Nacional de Tucumán.

»Peña Monné, J. L., Sampietro Vattuone, M. M., Maldonado, M. G., Cano, S. F. y Aguirre, M. G. (2016b). Patrimonio y conservación en el sitio arqueológico El Pichao (Noroeste Argentino). Trabajo presentado en el XIX Congreso Nacional de Arqueología Argentina, Tucumán, Argentina.

»Ramos, A. (1992). Sistemas aluviales braided. Sedimentología, 1, 67-106. 
» Rodríguez, M., Sampietro Vattuone, M. M. y Peña Monné, J. L. (2016). La antigua ciudad de Quilmes: contexto etnohistórico y geoarqueológico. En M. M. Sampietro-Vattuone y J. L. Peña-Monné (Eds.), Geoarqueología de los Valles Calchaquíes. Ocupaciones humanas y reconstrucciones paleoambientales del Holoceno (pp. 145-163). San Miguel de Tucumán: Laboratorio de Geoarqueología, Universidad Nacional de Tucumán.

» Rust, B. R. (1978). Depositional models for braided alluvium. Fluvial Sedimentology, 5, 605625.

» Sampietro Vattuone, M. M., y Peña Monné, J. L. (2016). Geomorphological dynamic changes during the Holocene through ephemeral stream analyses from Northwest Argentina. Catena, 147, 663-677. https://doi.org/10.1016/j.catena.2016.08.029

» Sampietro Vattuone, M. M., Peña Monné, J. L., Maldonado, M. G., Sancho Marcén, C., Báez, W., Sola, A. y Blasi, A. (2018). Cambios ambientales durante el Holoceno superior registrados en secuencias morfosedimentarias fluvio-eólicas del Valle de Santa María (Noroeste Argentino). Boletín Geológico y Minero, 129(4), 647-669. http://dx.doi.org/10.21701/bolgeomin.129.4.004

»Schávelzon, D. (1990). La restauración de arquitectura prehispánica en la Argentina. Notas para su historia. Runa, archive para las ciencias del hombre, 19(1), 83-93. http://revistascientificas. filo.uba.ar/index.php/runa/article/view/4272 (Acceso: 1 de enero, 2020).

»Schumm, S. A. (1985). Patterns of alluvial rivers. Annual Review of Earth and Planetary Sciences, 13(1), 5-27.

"Sosa, J. (2007). “Ruinas” de Quilmes, historia de un despropósito. Manuscrito inédito. https:// archivo.argentina.indymedia.org/uploads/2008/01/kilmes.pdf (Acceso: 22 de marzo, 2020). 